\title{
Natural History of Temporal Lobe Epilepsy: Antecedents and Progression
}

\author{
Garima Shukla ${ }^{1}$ and Asuri N. Prasad ${ }^{2}$ \\ ${ }^{1}$ Department of Neurology, All India Institute of Medical Sciences, New Delhi 110029, India \\ ${ }^{2}$ Departments of Pediatrics and Clinical Neurosciences, Schulich School of Medicine and Dentistry, Children's Hospital, \\ London Health Sciences Centre, London, ON, Canada N6A 5 W9
}

Correspondence should be addressed to Garima Shukla, garimashukla@hotmail.com

Received 21 September 2011; Revised 20 December 2011; Accepted 29 December 2011

Academic Editor: Seyed M. Mirsattari

Copyright (C) 2012 G. Shukla and A. N. Prasad. This is an open access article distributed under the Creative Commons Attribution License, which permits unrestricted use, distribution, and reproduction in any medium, provided the original work is properly cited.

Temporal lobe epilepsy represents the largest group of patients with treatment resistant/medically intractable epilepsy undergoing epilepsy surgery. The underpinnings of common forms of TLE in many instances begin in early life with the occurrence of an initial precipitating event. The first epileptic seizure often occurs after a variable latency period following this event. The precise natural history and progression following the first seizure to the development of TLE, its subsequent resolution through spontaneous remission or the development of treatment resistant epilepsy remain poorly understood. Our present understanding of the role played by these initial events, the subsequent latency to development of temporal lobe epilepsy, and the emergence of treatment resistance remains incomplete. A critical analysis of published data suggest that TLE is a heterogeneous condition, where the age of onset, presence or absence of a lesion on neuroimaging, the initial precipitating event, association with febrile seizures, febrile status epilepticus, and neurotropic viral infections influence the natural history and outcome. The pathways and processes through which these variables coalesce into a framework will provide the basis for an understanding of the natural history of TLE. The questions raised need to be addressed in future prospective and longitudinal observational studies.

\section{Introduction}

Amongst adult patients with medically intractable epilepsy, focal epilepsy from a temporal lobe focus represents the largest single etiology [1-4]. While only a small percentage $(<25 \%)$ among patients operated for temporal lobe epilepsy (TLE) are in the pediatric age group [5], it is well documented that most adults in surgical series have had a childhood onset of epilepsy. It has been suggested that a significant proportion of children with refractory epilepsy on the other hand may have TLE and, more specifically, may have hippocampal sclerosis (HS) on MRI (magnetic resonance imaging) [6]. There exist gaps in our understanding of the natural history of TLE and its progression, from its antecedents in fetal life and childhood, eventually culminating in a stage of medical refractoriness that is reached in adult life. Current understanding of the natural history of TLE identifies the need for well-designed prospective studies to elucidate risk factors and triggers $[7,8]$. Clinical information of this nature might provide additional avenues for interventional strategies to be investigated and developed.

In this paper we present a brief outline and review of prior published data on TLE and identify critical areas where additional information on the evolution of TLE can be prospectively derived. For the purpose of clarification, the term TLE used is inclusive of more common mesial temporal lobe epilepsy (mTLE), as well as other forms of neocortical temporal lobe epilepsy (nTLE), unless otherwise specified.

\section{Methods}

A Pubmed search strategy using the following terms "TLE and natural history; TLE and antecedents; TLE and benign; TLE and clinical and outcome" was adopted for the purpose of this review. The search yielded a total of 678 publications 
when the limits of "Human" and "English" were applied. Studies were selected on the basis of (1) whether patient selection criteria clearly defined TLE. We ascertained that each of the definitions used clearly either carried "mention of detailed semiological features of habitual seizures and latent period" or "resection of the temporal lobe for refractory epilepsy with outcome details" and (2) if the study mentioned any clinical details of antecedents or precipitating events that includes FS or FSE, age at onset, and time to refractoriness of epilepsy. After reviewing 89 abstracts and 23 full text articles reporting large series of patients with TLE, many of which were outcome studies of surgery for TLE we identified nine studies that documented details of past history obtained preoperatively.

A summary of key findings in the studies critical to this review is introduced in Table 1 .

\section{Results and Discussion}

3.1. Evidence for Role of "Initial Precipitating Events" IPEs. The significance of early IPEs among patients with TLE has been long recognized. The participants of Group 1 (for definition and natural history of mTLE) of the ILAE (International League Against Epilepsy) Commission on Neurosurgery observed that most surgical series reported "a high incidence of "IPEs" in the form of FS, trauma, hypoxia or intracranial infection". However the authors felt that these studies were "not definitive", since the detailed and exhaustive case histories that are required to determine frequency of the IPEs (antecedents) and time to onset as well as time to intractability of epilepsy might not be available from these retrospective series [9].

In an elegant study, French et al. presented a comparative analysis of data obtained from 193 patients with predefined clinical and EEG criteria to define TLE and that obtained from 164 "normal" individuals [10]. The authors identified reasonably "definite" or "probable" etiological factors in the past histories of $77.2 \%$ patients with TLE, compared with only $7.3 \%$ among the control population reporting birth abnormalities or other significant past history.

Clinical data regarding IPEs in childhood have been identified in surgical series that include patients with HS on MRI (magnetic resonance imaging) and underwent temporal lobectomy (TLY) for the same. The data presented by Harvey et al. however evaluated patients who did not undergo surgery [12]. In this group nearly $40 \%$ of patients with TLE confirmed the occurrence of an IPE, in the form of simple or complicated FS. A history of perinatal problems was reported in only a small proportion of patients $(<1 \%)$ by several investigators $[10,12,13,17]$ with the exception of the study by Ozkara et al. [14]. In the latter, the authors reported an antecedent history suggestive of birth asphyxia in 21 out of 62 patients (33.9\%), a significantly higher proportion. A history of FS was also noted in a majority of patients (70\%) among their group of postoperative patients with mTLE and MRI evidence of HS. In a study by Rathore et al., a similar proportion, that is, $(68.5 \%)$ of postoperative patients were found to have a documented history of FS, while only 2 out of 124 patients (1.6\%) had history of perinatal hypoxia [17]. In the largest series among the selected studies that were reviewed, Uijl et al. found history of FS in 37\% of the patients, while details of other IPEs were not described [15]. In a study of factors determining the development of treatment resistance among patients undergoing epilepsy surgery, Berg et al. are only able to provide data on history of febrile seizures, while information on other IPEs is lacking [8].

An analysis of these selected as well as other studies on surgical outcomes in TLE [18] leads one to the conclusion that there is little prospective data or agreement regarding IPEs amongst most published series. It is clear from these studies that there is a considerable variation encountered when comparing results from different studies even when similar clinical variables are considered. Differences in the documentation of historical details, different selection criteria for surgery, and the lack of prospectively collected information surrounding IPEs may serve as plausible reasons for the variation in information available. Thus, while perinatal critical events and febrile seizures appear to be known variables, no definitive conclusions other than a speculative inference regarding the potential role for IPE's can be drawn from these published studies.

3.2. What Is the Latency to Development of Epilepsy in TLE Following IPE? Janszky et al. studied the age at onset of a homogenous group of 118 patients with mTLE and history of childhood febrile convulsions (CFCs) and reported the age at epilepsy onset to be a trimodal pattern with peaks at ages of 5.5, 15.3, and 26.7 years. These authors observed that the "latent/silent" period between occurrence of CFCs and epilepsy onset was significantly longer in patients with childhood onset, when compared to patients with an adolescent onset of mTLE [19]. Harvey et al. reported a bimodal pattern of the age at onset in a much smaller group of TLE patients with HS on MRI. The mean age observed was $5.1 \pm$ 3.8 years with two peaks identified, the first occurring early (second year) and the second, late (ninth year) during childhood years [12]. A younger age of onset of epilepsy also appears to bear a strong correlation with MRI findings of HS, even controlling for disease duration and history of FS $[8,20]$. In a study aimed at evaluating predictive prognostic factors for a cohort of patients with sporadic TLE associated with either HS or a nonlesional TLE Aguglia et al. observed an older average age at onset (among 100 seizure free) patients to be $33.5 \pm 19.9$ years in comparison to an average age of $17.2 \pm 14.4$ years (in 90 non-seizure-free) patients on univariate analysis. Furthermore, an older age at onset was found to be the single independent prognostic factor for good seizure outcome, even on multivariate analysis [21]. Heuser and colleagues propose the occurrence of mTLE among patients with history of FS (mTLE-FS) as a separate entity based on the observation that the age at epilepsy onset is significantly lower in this group as compared to those mTLE patients who do not have prior history of FS [22].

It is evident from these studies that TLE, dominantly represented by patients with HS on MRI, has a variable 
TABLE 1: Summary of selected studies on TLE and relationship to IPE.

\begin{tabular}{|c|c|c|c|c|}
\hline Study & $N$ & Criteria for diagnosis of TLE & IPE reported & $\begin{array}{l}\text { Patients with TLE } \\
\text { with positive history } \\
(\%)\end{array}$ \\
\hline \multirow{6}{*}{ French $[10]$} & \multirow{6}{*}{67} & $\begin{array}{l}\text { Mesial temporal onset on depth } \\
\text { EEG }\end{array}$ & $\begin{array}{l}\text { Seizures in infancy/early } \\
\text { childhood }\end{array}$ & $54[81]$ \\
\hline & & Nonlesional MRI & $\sim \mathrm{FS}$ & $52[78]$ \\
\hline & & $\begin{array}{l}\text { Seizure freedom since unilateral } \\
\text { TLY, at least } 2 \text { years }\end{array}$ & $\sim$ Afebrile-Head & 02 \\
\hline & & & Head trauma & 10 \\
\hline & & & Birth trauma & 02 \\
\hline & & & Other maternal factors & 02 \\
\hline \multirow{4}{*}{ Tassi [11] } & \multirow{4}{*}{243} & \multirow{4}{*}{$\begin{array}{l}\text { Surgery confined to temporal } \\
\text { lobe, with histopathological data } \\
\text { on neocortex and hippocampus }\end{array}$} & Febrile seizures [FS] & \\
\hline & & & FS in patients with HS & $61[25]$ \\
\hline & & & $\begin{array}{l}\text { FS in patients with HS } \\
\text { only }\end{array}$ & $15 / 34[44]$ \\
\hline & & & $\begin{array}{l}\text { FS in patients with } \\
\text { MCD }\end{array}$ & $50 / 110[45]$ \\
\hline \multirow{14}{*}{ Harvey [12] } & \multirow{14}{*}{$\begin{array}{l}63 \text { [new onset } \\
\text { TLE-age of onset }<15 \\
\text { years] }\end{array}$} & \multirow{14}{*}{$\begin{array}{l}\text { Agreement among } 3 \text { neurologists } \\
\text { from clinical and investigational } \\
\text { data; ictal EEG "gold standard" }\end{array}$} & Perinatal problems & \\
\hline & & & Head injury & $24[38]$ \\
\hline & & & Bacterial meningitis & 1 \\
\hline & & & Viral encephalitis & 1 \\
\hline & & & FS & 4 \\
\hline & & & Simple & 1 \\
\hline & & & Complicated & \\
\hline & & & Respiratory arrest & 6 \\
\hline & & & Hypertensive & 7 \\
\hline & & & Encephalopathy & 2 \\
\hline & & & Prolonged focal FS & \\
\hline & & & Infantile spasms & 1 \\
\hline & & & & 1 \\
\hline & & & & 1 \\
\hline \multirow{5}{*}{ Sztriha [13] } & \multirow{5}{*}{$\begin{array}{l}30 \text { [new onset } \\
\text { TLE-age of onset } \\
<14 \text { years] }\end{array}$} & \multirow{5}{*}{$\begin{array}{l}\text { Agreement amongst } 2 \\
\text { investigators based on clinical } \\
\text { and investigational data; no } \\
\text { alternative diagnosis likely }\end{array}$} & Antecedent illness & $5[16.6]$ \\
\hline & & & Perinatal HIE & 1 \\
\hline & & & Encephalitis & 1 \\
\hline & & & Traumatic brain injury & 2 \\
\hline & & & Complex FS & 1 \\
\hline \multirow{9}{*}{ Ozkara [14] } & \multirow{9}{*}{165} & \multirow{9}{*}{$\begin{array}{l}\text { Mesial TLE with HS on MRI; } \\
\text { postoperative follow-up data for } \\
>1 \text { year available }\end{array}$} & FS & $116[70.3]$ \\
\hline & & & Risk factors & $62[37.6]$ \\
\hline & & & [antecedents] & 27 \\
\hline & & & Head trauma & 21 \\
\hline & & & Birth asphyxia & 11 \\
\hline & & & Neonatal infections & 1 \\
\hline & & & Kernicterus & 1 \\
\hline & & & Near drowning & 1 \\
\hline & & & Heat stroke & \\
\hline Uijl et al. [15] & 484 & $\begin{array}{l}\text { Epilepsy surgery patients who } \\
\text { underwent TLY }\end{array}$ & FS & $180[37]$ \\
\hline Jeong et al. [16] & 227 & $\begin{array}{l}\text { mTLE } \\
\text { With HS on MRI and anterior } \\
\text { temporal onset on ictal EEG; } \\
\text { with normal MRI but clear } \\
\text { mesial temporal onset on } \\
\text { invasive electrode ictal recordings }\end{array}$ & FS & $99[43.6]$ \\
\hline
\end{tabular}


TABle 1: Continued.

\begin{tabular}{|c|c|c|c|c|}
\hline Study & $N$ & Criteria for diagnosis of TLE & IPE reported & $\begin{array}{l}\text { Patients with TLE } \\
\text { with positive history } \\
(\%)\end{array}$ \\
\hline \multirow{7}{*}{ Rathore et al. [17] } & \multirow{7}{*}{124} & \multirow{7}{*}{$\begin{array}{l}\text { Postoperative mTLE with } \\
\text { histopathologically proven HS }\end{array}$} & Typical FS & $85[68.5]$ \\
\hline & & & Atypical IPE & 19 \\
\hline & & & Meningoencephalitis & 10 \\
\hline & & & Febrile status & 6 \\
\hline & & & Epilepticus & \\
\hline & & & Perinatal hypoxia & 2 \\
\hline & & & Neonatal seizures & 1 \\
\hline Berg et al. [8] & $\begin{array}{l}215[\text { Total patients } \\
\text { analyzed }=333]\end{array}$ & $\begin{array}{l}\text { Refractory partial epilepsy and } \\
\text { HS on MRI, having undergone } \\
\text { resective surgery for same }\end{array}$ & FS & $95[44.2]$ \\
\hline
\end{tabular}

FS: febrile seizures, mTLE: mesial temporal lobe sclerosis, HS: hippocampal sclerosis, HIE: hypoxic ischemic encephalopathy, FSE: febrile status epilepticus, TLY: temporal lobectomy, MCD: malformations of cortical development, and IPE: Initial precipitating event.

age at onset. Despite suggestions that a prior cerebral insult predisposes an individual to development of TLE, at least among a subgroup of patients, the latency to the onset of epilepsy remains variable. In addition, the latency to the development of the more commonly encountered refractory form of epilepsy remains largely unpredictable in the individual setting.

Thus, the evidence from published case series suggests a role for the duration of epilepsy from the time of occurrence of the IPE in determining development of HS and prospects for a remission. Prospective cohort studies among subgroups of patients with perinatal brain injury and those with FS and FSE will be necessary to determine whether distinct subtypes of TLE can be delineated based on the age of onset of epilepsy and the occurrence of FS/FSE.

3.3. When Does TLE Become Refractory to Medications? It is well known that among patients with TLE as well as other focal epilepsies, treatment resistance or refractoriness to antiepileptic drugs (AEDs) appears after a significant time lapse or latency from onset of first seizure, at least in a subset of patients. The mechanisms underlying this "latent period" remain largely unidentified.

In a study analyzing information obtained from 333 patients with medically refractory partial epilepsy, Berg et al. could identify the average time to intractability as 9.1 years (median 5 and range $0-46$ years) in 282 patients. The authors defined "time to intractability" as "time between occurrence of second seizure and failure of second AED". On multivariate logistic regression analysis, the authors found that the age at onset provided the most significant correlation of this latency period; that is, earlier the age at onset, longer the latency period to intractability [8]. In another retrospective study of 162 patients fulfilling the inclusion criteria of TLE followed up for at least 2 years, the best model to predict refractoriness to medication included the variable "failure of first AED trial," with a positive predictive value of 0.89 (95\% CI 0.76, 0.96) and negative predictive value of 0.95 (95\% CI 0.87, 0.99) [23].
It has been suggested that the time to establish failure to respond to an adequate trial of a second AED (or even the first AED) does not necessarily imply "latency to intractability", as intractability may have been present long before the current standard of "proof" is attained [24]. Any direct study of human TLE, suggesting that it is a progressive condition, is not yet available. Confounding factors like the genetic profile of the individual (susceptibility genes, genetic polymorphisms), epigenetic modifiers, underlying systemic disease, effect of epileptic discharges on human brain, neuropathological effects of seizure-related systemic perturbations, trauma, AED effects (including inappropriate drugs), and multiple drug-resistant transporters will no doubt influence any estimate [24].

3.4. What Is the Role of Febrile Seizures, Febrile Status Epilepticus, Human Herpes Virus Infection, and TLE-The Associations? FS have long been known to be associated with the future development of epilepsy, especially mTLE $[25,26]$. While retrospective studies have favored this association, prospective studies thus far have failed to confirm a causal association between the two [27-29]. In the retrospective study by Abou-Khalil et al., amongst 47 patients operated for temporal resection, a subgroup of 19 patients with history of FS showed excellent surgical outcome (85\% seizure-free) in comparison to the remaining 28 patients $(32 \%)$ who did not have prior history of FS [25]. Importantly, almost all patients had prolonged FS (mean duration 4 hours, range 20 minutes to 24 hours). This group also had a significantly lower age at surgery. A major selection bias could potentially have contributed to this difference, as the history of FS may have well influenced the decision to take up those patients with HS for TLY, resulting in an expectedly good surgical outcome.

It is then interesting to note the findings of a large prospective study on patients with a history of FS obtained through questionnaires administered to parents of infants born over a week in the UK. The questionnaires were administered when the children were 5 years of age $(82 \%$ 
responses obtained) and when they were 10 years of age (93\% responses obtained) [30]. The investigators found that information was available for 14,676 children in the cohort. Nearly $382(2.7 \%)$ children experienced at least one FS. Thirteen of these $382(3.4 \%)$ experienced one or more afebrile seizures, nine of whom developed epilepsy. A higher proportion of children with complex FS (6/95) rather than simple FS (3/287) developed epilepsy, the risk being highest for those who had had focal FS $(5 / 17 ; x 2=$ $399, P<0001)$. Three of the 32 children who had prolonged FS also developed afebrile complex partial seizures (CPSs). The authors concluded that epilepsy developing after FS in childhood is not as common as expected from hospital studies, rather rare.

A systematic review of 63 studies on the outcome of pediatric status epilepticus found that the risk of sequelae in unprovoked and febrile convulsive status epilepticus (CSE) is low. The same review finds evidence that CSE, especially febrile CSE, might cause hippocampal injury, although its role in the development of MTS is unknown [31].

Additional lines of evidence favor a role for human herpes virus 6 (HHV 6) in the causation of mTLE based on the detection of the viral antigen in resected temporal lobe tissues at surgery, and exposure to the virus in the early childhood is exceedingly common. Detection of the virus or viral antigen in body fluids of children with febrile seizures has ranged from 8 to $40 \%$ in different studies [32]. The rate of HHV6 detection in resected temporal lobe tissue from surgical specimens in patients undergoing temporal lobectomy has varied greatly $[33,34]$. Recently, Niehusmann et al. carried out molecular and histochemical analysis of excised pathological specimens in patients undergoing temporal lobectomy for pharmacoresistant epilepsy. They reported a 55\% positivity for HHV 6 on nested PCR experiments in surgically excised temporal lobe tissue in a group of 9 TLE patients who met strict criteria of a welldefined history of encephalitis in childhood, compared to none among 26 others with TLE without IPEs, TLE with history of complex FS, and lesional TLE with 10 autopsy controls [35]. The authors suggest that while their findings argue against a causative role for HHV6 in TLE with a history of complex FS, the viral infection may play an important role in TLE with a history of encephalitis, despite the obvious heterogeneity of postencephalitic patients in their series. They suggest that, in patients with encephalitis of different cause, the presence of HHV6 may facilitate the development of TLE; however, they caution that it may "neither be sufficient or necessary" factor. It is also interesting to note that the presence of HHV6 was associated with significant gliosis in the temporal lobe tissue being examined, a feature which points to a role for inflammation in TLE $[35,36]$.

Interval data analysis from the FEBSTAT study, a multicenter prospective study on children 1 month to 5 year in age, designed to study the consequences of FSE, indicates that primary HHV-6B may be an important cause of FSE [37].

The evidence thus far offers weak associations between the occurrence of FS, FSE, and viral infections (in particular HHV-6) in childhood and subsequent development of TLE. It is also suggested that age and coexistent neuropathology may be added as contributory factors in the variable rates of detection of herpesvirus DNA in surgically resected tissue [38].

3.5. Are All Forms of TLE Medically Intractable? Spontaneous Remission and the Development of Treatment Resistance. An "older age at onset" is the only independent predictor of 2 -year seizure freedom or "remission" among patients with nonlesional TLE [21]. Studying 190 patients with clinically diagnosed TLE, with a mean followup of 11 years, the authors found that more than half of the patients underwent spontaneous remissions. Although occurrence of FS and HS on MRI was found to be predictors of poor prognosis on univariate analysis, these did not attain significance on multivariate analysis.

Spooner et al., in a prospective study on 64 patients with TLE followed up for a median of 13 years, found $19(31 \%)$ to have attained 5-15-year remission and successfully remained off treatment while the remainder (69\%) continued to have seizures and had to be considered for epilepsy surgery evaluation, the only predictor of significance for continued seizures, being a lesion on MRI [39].

Both these studies published nearly 15 years apart suggest similar facts about remissions in TLE that a sizeable proportion of patients with an older age of onset do remit, and that the presence of lesions on MRI and a younger age at onset predict lower chance of remission.

3.6. Are There Different Subtypes of TLE? A review of the literature surrounding TLE clearly suggests that the etiology varies depending on age of onset. The maximal information regarding etiology has been obtained from pathological studies on surgically resected tissue in individuals undergoing anterior temporal lobectomy (ATL). The existence of other forms of TLE where the outcome is better than the more common form of pharmacoresistant TLE is also being recognized (Benign TLE and Familial TLE).

3.7. TLE in Infants and Children. The findings of a recently published study suggest that the most frequently reported pathology in childhood onset TLE who develop medically refractory epilepsy consists of dual pathology in the form of a neocortical lesion associated with HS $(80 \%$ of cases accounted for by cortical dysplasia or tumors such as gangliogliomas with HS). Isolated malformations of cortical development (MCD), gangliogliomas without hippocampal pathology, accounted for the remainder [40]. In infants, HS tends to be even less frequent, with the majority of the pathology reported consisting of nonprogressive lesions such as MCD, hamartomas, and low grade tumors such as dysembryoplastic neuroepithelial tumors (DNET) [41].

3.8. Temporal Lobe Epilepsy in Adults. The etiologies in adult onset TLE differ from those of childhood onset. While the epidemiological studies of late onset TLE point to infective, vascular (arteriovenous malformation, cavernous hemangioma, meningioangiomatosis), tumoral, traumatic, and in older individuals ( $>64$ years of age) neurodegenerative 
etiologies, the most frequently observed and reported pathology is HS. The causes leading to adult TLE have been less frequently reported $[42,43]$. It is of interest that the etiologies in those individuals who developed TLE with an age of onset beyond 20 years differ further from those individuals developing TLE in late adulthood (often $>60-65$ years). In a recent study, Soeder et al. identified limbic encephalitis (LE) associated with paraneoplastic and nonparaneoplastic (autoimmune) conditions (25\%) as constituting the largest group, followed by HS that was preceded by an IPE (22\%). Tumors (DNET, ganglioglioma, and other low-grade tumors) and amygdalar lesions made up constituted (14\% and 135), respectively. Finally, a miscellaneous group (24\%) was made of patients with posttraumatic lesions, cavernomas, chronic herpes simplex encephalitis, and progressive tumors (anaplastic oligodendroglioma, glioblastoma multiforme, and astrocytomas) [43].

3.9. Benign TLE. The Italian group of Labate, Gambardella, Aguglia, and colleagues have addressed various issues related to "benign mTLE" in great detail [44-46]. They described this entity for patients, who were "seizure free or had auras or not more than 2 disabling (CPSs and/or secondarily generalized) seizures in 24 months, with or without appropriate medications" [44].

In a study of 101 patients diagnosed as benign TLE, they found MRI evidence of unilateral MTS in 39 (38.6\%) patients. The antecedent history of febrile seizures alone predicted the association with MTS in this group of patients with benign TLE [46].

It has, thus, been clearly demonstrated that neither clinical presentation with features of TLE nor MRI evidence of MTS is determinant of future refractoriness of epilepsy in a large proportion of patients with TLE.

3.10. Familial TLE. First described by Berkovic and colleagues in 38 patients from 13 families in Australia, familial TLE has been recognized as a benign syndrome with typical temporal lobe seizures and good prognosis [47]. In a recent report by the same group, data from 20 new mTLE families (51 affected individuals) were presented. The epilepsies in these families were found to be generally benign, and history of febrile seizures was infrequent $(9.8 \%)$. No evidence of HS or MCD was present on brain imaging. A single individual underwent ATL, with subsequent seizure freedom and histopathological evidence of HS was not found [48]. Santos and colleagues reported 15 families with TLE, 14 of which manifested with features of mTLE and one family with nTLE. The authors found marked genetic heterogeneity among the families. This study is published in abstract format and no data on course of the epilepsy has been presented [49]. Within this group of patients with a relatively benign outcome, pathogenic mutations in the LGI 1 (leucine-rich glioma-inactivated 1) gene have been identified in patients with a partial epilepsy syndrome with auditory features (both autosomal dominant and sporadic forms). The existence of genetic heterogeneity in this group is well documented $[50,51]$.

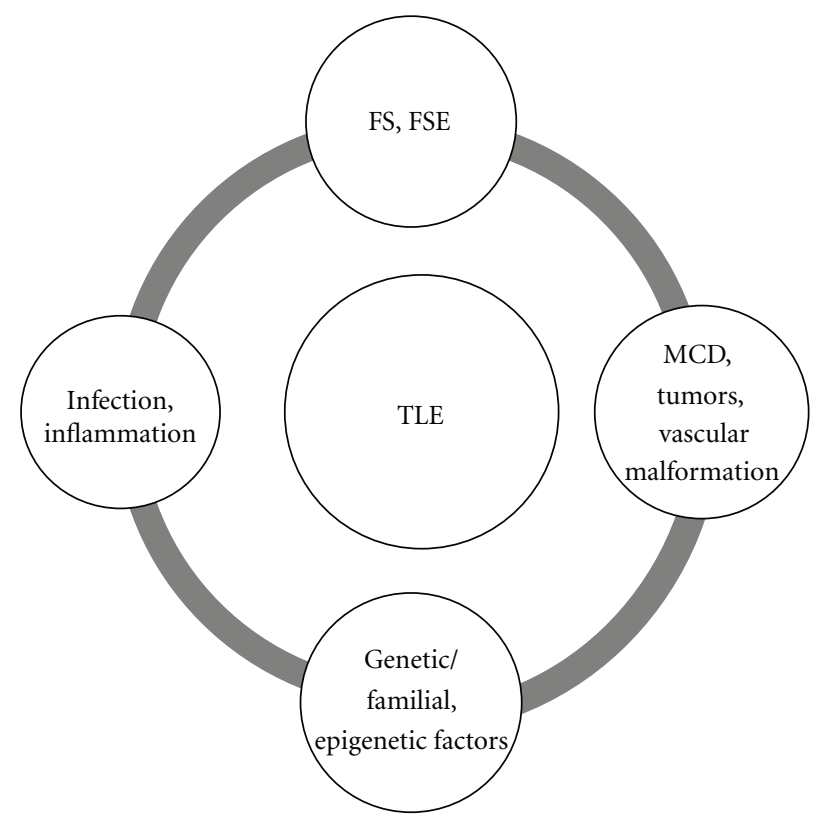

Figure 1: The figure summarizes the key antecedents whose interplay determines the evolution and progression to temporal lobe epilepsy (TLE). TLE: temporal lobe epilepsy, FS: febrile seizures, FSE: febrile status epilepticus, and $\mathrm{MCD}=$ malformations of cortical development.

\section{Conclusions and Future Directions}

A critical look at the evidence thus far published on TLE offers conflicting conclusions. While no definitive causal associations can be established, there does not appear strong evidence to support the existence of a single common pathway to the development of TLE and medical intractability. The most important conclusion that one can draw is that TLE is not a homogeneous entity. Rather, there may be several subsets that could be characterized on the basis of the following features: (1) age of onset of epilepsy (early versus late) (2) the presence or absence of a lesion on imaging (lesional versus nonlesional), (3) the nature of the IPE, (4) the occurrence of FS and FSE, (5) genetic and familial predisposition, and finally (6) response to treatment and outcome. These subsets clearly differ in the occurrence of spontaneous remission and progression to intractability. Any combination and interaction within different factors probably confer susceptibility as well as development and progression to TLE (Figure 1).

The current body of literature on the subject is vast and confusing at times. The limitations of most studies include the retrospective nature, the lack of longitudinal and observational studies, and weaknesses in study design. Single-center studies with poorly defined criteria for selection and inherent biases in patient selection further add to the challenges in interpretation of results. Several important questions that have been raised need to be addressed in carefully designed studies. These questions could be addressed through careful assessment of patients from the index event of the first seizure by epileptologists. In 
this context first seizure clinics at tertiary care centers will prove to be useful. Longitudinal observation of selected cohorts of patients sharing IPE's etiologies will form the groups where specialized high-resolution imaging and genetic studies should be considered. Tracking the patients to emergence of treatment resistance and eventual surgery in some will be important in identifying benign versus poor outcomes. Postsurgical evaluation of pathological material and specialized studies will further clarify role of infection and inflammation. Animal models could be developed to clarify questions pertaining to epileptogenesis, establish, and explore the usefulness of treatment interventions.

Future prospective studies will need to be multicenter and prospective in nature, perhaps undertaken by teams of investigators, with attention to study design. Such studies should take into account not only the factors discussed, but additionally be prepared to take a multipronged approach in investigating genetic and epigenetic factors that influence the development of an epileptogenic network that eventually leads to the development of different forms of TLE.

\section{Acknowledgment}

The authors wish to acknowledge and thank Shauna Konrad, Clinical Librarian, J. C. Rathbun Library/Stevens Health Sciences Library for her help in obtaining access to several articles in the preparation of this paper.

\section{References}

[1] H. Gastaut, J. L. Gastaut, E. G. E. Goncalves Silva, and G. R. Fernandez Sanchez, "Relative frequency of different types of epilepsy: a study employing the classification of the international league against epilepsy," Epilepsia, vol. 16, no. 3, pp. 457-461, 1975.

[2] M. Manford, Y. M. Hart, J. W. Sander, and S. D. Shorvon, "National general practice study of epilepsy (NGPSE): partial seizure patterns in a general population," Neurology, vol. 42, no. 10, pp. 1911-1917, 1992.

[3] R. Ottman, "Genetics of the partial epilepsies: a review," Epilepsia, vol. 30, no. 1, pp. 107-111, 1989.

[4] J. Engel Jr., "Introduction to temporal lobe epilepsy," Epilepsy Research, vol. 26, no. 1, pp. 141-150, 1996.

[5] S. Spencer, "Mesial temporal sclerosis: electroclinical and pathophysiological correlations and application to limbic epilepsy in childhood," in Limbic Seizures in Children, G. A. Munari, A. Beaumanoir, and L. Mira, Eds., John Libbey, Eastleigh, UK, 2001.

[6] F. Cormack, J. H. Cross, E. Isaacs et al., "The development of intellectual abilities in pediatric temporal lobe epilepsy," Epilepsia, vol. 48, no. 1, pp. 201-204, 2007.

[7] A. T. Berg, "The natural history of mesial temporal lobe epilepsy," Current Opinion in Neurology, vol. 21, no. 2, pp. 173178, 2008.

[8] A. T. Berg, J. Langfitt, S. Shinnar et al., "How long does it take for partial epilepsy to become intractable?" Neurology, vol. 60, no. 2, pp. 186-190, 2003.

[9] H. G. Wieser, "ILAE commission report. Mesial temporal lobe epilepsy with hippocampal sclerosis," Epilepsia, vol. 45, no. 6, pp. 695-714, 2004.
[10] J. A. French, P. D. Williamson, V. M. Thadani et al., "Characteristics of medial temporal lobe epilepsy: I. Results of history and physical examination," Annals of Neurology, vol. 34, no. 6, pp. 774-780, 1993.

[11] L. Tassi, A. Meroni, F. Deleo et al., "Temporal lobe epilepsy: neuropathological and clinical correlations in 243 surgically treated patients," Epileptic Disorders, vol. 11, no. 4, pp. 281292, 2009.

[12] A. S. Harvey, S. F. Berkovic, J. A. Wrennall, and I. J. Hopkins, "Temporal lobe epilepsy in childhood: clinical, EEG, and neuroimaging findings and syndrome classification in a cohort with new-onset seizures," Neurology, vol. 49, no. 4, pp. 960968, 1997.

[13] L. Sztriha, A. K. Gururaj, A. Bener, and M. Nork, “Temporal lobe epilepsy in children: etiology in a cohort with new-onset seizures," Epilepsia, vol. 43, no. 1, pp. 75-80, 2002.

[14] C. Ozkara, M. Uzan, G. Benbir et al., "Surgical outcome of patients with mesial temporal lobe epilepsy related to hippocampal sclerosis," Epilepsia, vol. 49, no. 4, pp. 696-699, 2008.

[15] S. G. Uijl, F. S. Leijten, J. B. Arends, J. Parra, A. C. van Huffelen, and K. G. Moons, "Prognosis after temporal lobe epilepsy surgery: the value of combining predictors," Epilepsia, vol. 49, no. 8, pp. 1317-1323, 2008.

[16] S. W. Jeong, S. K. Lee, K. S. Hong, K. K. Kim, C. K. Chung, and H. Kim, "Prognostic factors for the surgery for mesial temporal lobe epilepsy: longitudinal analysis," Epilepsia, vol. 46, no. 8, pp. 1273-1279, 2005.

[17] C. Rathore, A. George, C. Kesavadas, P. S. Sarma, and K. Radhakrishnan, "Extent of initial injury determines language lateralization in mesial temporal lobe epilepsy with hippocampal sclerosis (MTLE-HS)," Epilepsia, vol. 50, no. 10, pp. 22492255, 2009.

[18] S. Wiebe, W. T. Blume, J. P. Girvin, and M. Eliasziw, "A randomized, controlled trial of surgery for temporal-lobe epilepsy," The New England Journal of Medicine, vol. 345, no. 5, pp. 311-318, 2001.

[19] J. Janszky, I. Janszky, and A. Ebner, "Age at onset in mesial temporal lobe epilepsy with a history of febrile seizures," Neurology, vol. 63, no. 7, pp. 1296-1298, 2004.

[20] K. G. Davies, B. P. Hermann, F. C. Dohan Jr., K. T. Foley, A. J. Bush, and A. R. Wyler, "Relationship of hippocampal sclerosis to duration and age of onset of epilepsy, and childhood febrile seizures in temporal lobectomy patients," Epilepsy Research, vol. 24, no. 2, pp. 119-126, 1996.

[21] U. Aguglia, E. Beghi, A. Labate et al., "Age at onset predicts good seizure outcome in sporadic non-lesional and mesial temporal sclerosis based temporal lobe epilepsy," Journal of Neurology, Neurosurgery and Psychiatry, vol. 82, no. 5, pp. 555$559,2011$.

[22] K. Heuser, M. Cvancarova, L. Gjerstad, and E. Tauboll, "Is temporal lobe epilepsy with childhood febrile seizures a distinctive entity? A comparative study," Seizure, vol. 20, no. 2, pp. 163-166, 2011.

[23] D. J. Dlugos, M. D. Sammel, B. L. Strom, and J. T. Farrar, "Response to first drug trial predicts outcome in childhood temporal lobe epilepsy," Neurology, vol. 57, no. 12, pp. 22592264, 2001.

[24] W. T. Blume, “The progression of epilepsy," Epilepsia, vol. 47, no. 1, supplement, pp. 71-78, 2006.

[25] B. Abou-Khalil, E. Andermann, F. Andermann, A. Olivier, and L. F. Quesney, "Temporal lobe epilepsy after prolonged febrile convulsions: excellent outcome after surgical treatment," Epilepsia, vol. 34, no. 5, pp. 878-883, 1993. 
[26] F. Cendes, F. Andermann, F. Dubeau et al., "Early childhood prolonged febrile convulsions, atrophy and sclerosis of mesial structures, and temporal lobe epilepsy: an MRI volumetric study," Neurology, vol. 43, no. 6, pp. 1083-1087, 1993.

[27] J. F. Annegers, W. A. Hauser, S. B. Shirts, and L. T. Kurland, "Factors prognostic of unprovoked seizures after febrile convulsions," The New England Journal of Medicine, vol. 316, no. 9, pp. 493-498, 1987.

[28] A. T. Berg, S. Shinnar, S. R. Levy, and F. M. Testa, "Childhoodonset epilepsy with and without preceding febrile seizures," Neurology, vol. 53, no. 8, pp. 1742-1748, 1999.

[29] P. Camfield, C. Camfield, K. Gordon, and J. Dooley, "What types of epilepsy are preceded by febrile seizures? A population-based study of children," Developmental Medicine and Child Neurology, vol. 36, no. 10, pp. 887-892, 1994.

[30] C. M. Verity and J. Golding, "Risk of epilepsy after febrile convulsions: a national cohort study," British Medical Journal, vol. 303, no. 6814, pp. 1373-1376, 1991.

[31] M. Raspall-Chaure, R. F. Chin, B. G. Neville, and R. C. Scott, "Outcome of paediatric convulsive status epilepticus: a systematic review," The Lancet Neurology, vol. 5, no. 9, pp. 769-779, 2006.

[32] J. G. Millichap and J. J. Millichap, "Role of viral infections in the etiology of febrile seizures," Pediatric Neurology, vol. 35, no. 3, pp. 165-172, 2006.

[33] D. Donati, N. Akhyani, A. Fogdell-Hahn et al., "Detection of human herpesvirus-6 in mesial temporal lobe epilepsy surgical brain resections," Neurology, vol. 61, no. 10, pp. 1405-1411, 2003.

[34] J. Fotheringham, D. Donati, N. Akhyani et al., "Association of human herpesvirus-6B with mesial temporal lobe epilepsy," PLoS Medicine, vol. 4, no. 5, article e180, 2007.

[35] P. Niehusmann, T. Mittelstaedt, C. G. Bien et al., "Presence of human herpes virus 6 DNA exclusively in temporal lobe epilepsy brain tissue of patients with history of encephalitis," Epilepsia, vol. 51, no. 12, pp. 2478-2483, 2010.

[36] H. Uesugi, H. Shimizu, T. Maehara, N. Arai, and H. Nakayama, "Presence of human herpesvirus 6 and herpes simplex virus detected by polymerase chain reaction in surgical tissue from temporal lobe epileptic patients," Psychiatry and Clinical Neurosciences, vol. 54, no. 5, pp. 589-593, 2000.

[37] W. H. Theodore, L. Epstein, W. D. Gaillard, S. Shinnar, M. S. Wainwright, and S. Jacobson, "Human herpes virus 6B: a possible role in epilepsy?" Epilepsia, vol. 49, no. 11, pp. 18281837, 2008.

[38] O. Eeg-Olofsson, T. Bergstrom, F. Andermann, E. Andermann, A. Olivier, and B. Rydenhag, "Herpesviral DNA in brain tissue from patients with temporal lobe epilepsy," Acta Neurologica Scandinavica, vol. 109, no. 3, pp. 169-174, 2004.

[39] C. G. Spooner, S. F. Berkovic, L. A. Mitchell, J. A. Wrennall, and A. S. Harvey, "New-onset temporal lobe epilepsy in children: lesion on MRI predicts poor seizure outcome," Neurology, vol. 67, no. 12, pp. 2147-2153, 2006.

[40] C. Bocti, Y. Robitaille, P. Diadori et al., "The pathological basis of temporal lobe epilepsy in childhood," Neurology, vol. 60, no. 2, pp. 191-195, 2003.

[41] B. F. Bourgeois, "Temporal lobe epilepsy in infants and children," Brain and Development, vol. 20, no. 3, pp. 135-141, 1998.

[42] H. K. Wolf, M. G. Campos, J. Zentner et al., "Surgical pathology of temporal lobe epilepsy. Experience with 216 cases," Journal of Neuropathology and Experimental Neurology, vol. 52, no. 5, pp. 499-506, 1993.
[43] B. M. Soeder, U. Gleissner, H. Urbach et al., "Causes, presentation and outcome of lesional adult onset mediotemporal lobe epilepsy," Journal of Neurology, Neurosurgery and Psychiatry, vol. 80, no. 8, pp. 894-899, 2009.

[44] A. Labate, A. Gambardella, E. Andermann et al., "Benign mesial temporal lobe epilepsy," Nature Reviews Neurology, vol. 7, no. 4, pp. 237-240, 2011.

[45] A. Gambardella, I. Manna, A. Labate et al., "GABA(B) receptor 1 polymorphism (G1465A) is associated with temporal lobe epilepsy," Neurology, vol. 60, no. 4, pp. 560-563, 2003.

[46] A. Labate, P. Ventura, A. Gambardella et al., "MRI evidence of mesial temporal sclerosis in sporadic "benign" temporal lobe epilepsy," Neurology, vol. 66, no. 4, pp. 562-565, 2006.

[47] S. F. Berkovic, A. McIntosh, R. A. Howell, A. Mitchell, L. J. Sheffield, and J. L. Hopper, "Familial temporal lobe epilepsy: a common disorder identified in twins," Annals of Neurology, vol. 40, no. 2, pp. 227-235, 1996.

[48] D. E. Crompton, I. E. Scheffer, I. Taylor et al., "Familial mesial temporal lobe epilepsy: a benign epilepsy syndrome showing complex inheritance," Brain, vol. 133, no. 11, pp. 3221-3231, 2010.

[49] N. F. Santos, S. C. Sousa, E. Kobayashi et al., "Clinical and genetic heterogeneity in familial temporal lobe epilepsy," Epilepsia, vol. 43, no. 5, supplement, p. 136, 2002.

[50] C. Nobile, R. Michelucci, S. Andreazza, E. Pasini, S. C. Tosatto, and P. Striano, "LGI1 mutations in autosomal dominant and sporadic lateral temporal epilepsy," Human Mutation, vol. 30, no. 4, pp. 530-536, 2009.

[51] R. Michelucci, J. J. Poza, V. Sofia et al., "Autosomal dominant lateral temporal epilepsy: clinical spectrum, new epitempin mutations, and genetic heterogeneity in seven european families," Epilepsia, vol. 44, no. 10, pp. 1289-1297, 2003. 


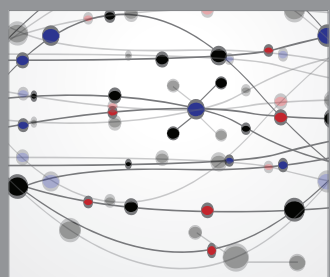

The Scientific World Journal
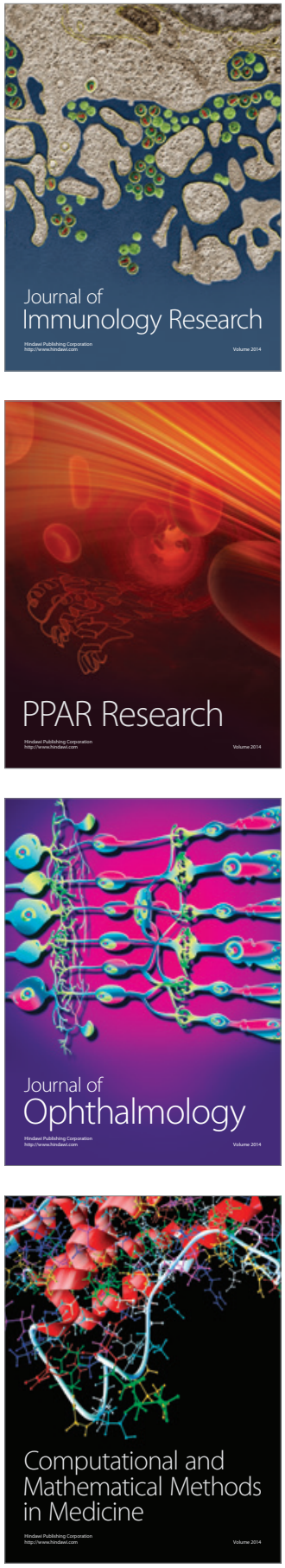

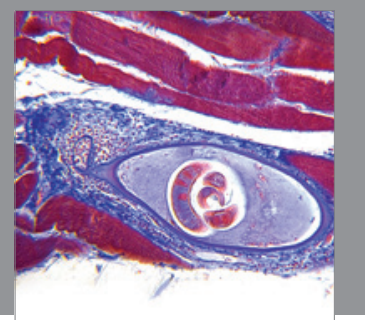

Gastroenterology

Research and Practice
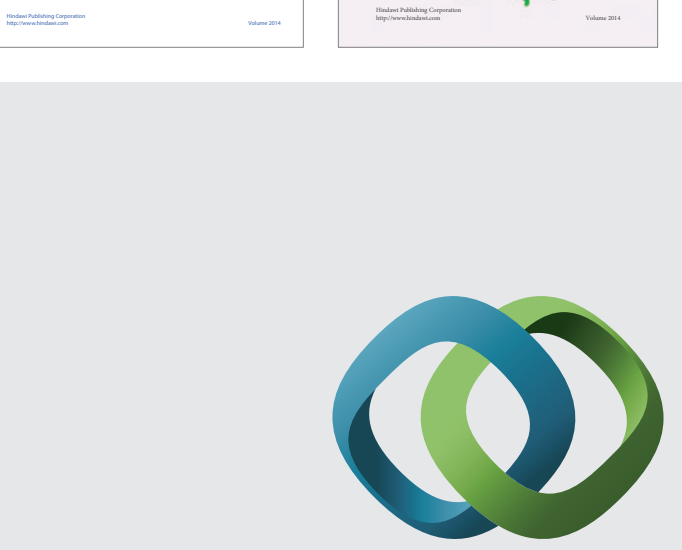

\section{Hindawi}

Submit your manuscripts at

http://www.hindawi.com
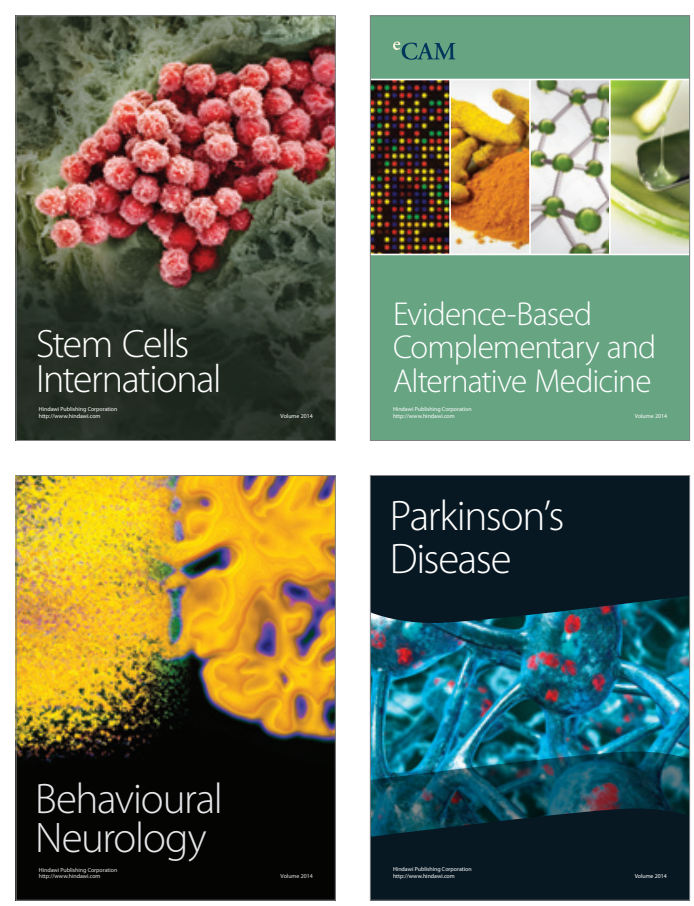

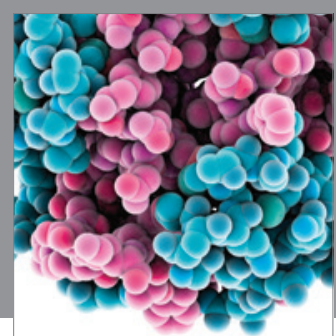

Journal of
Diabetes Research

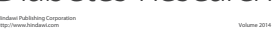

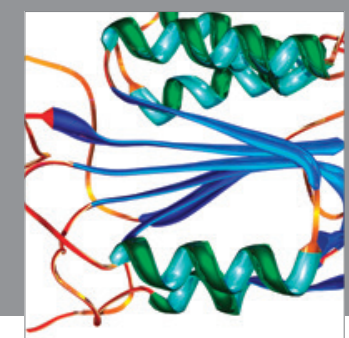

Disease Markers
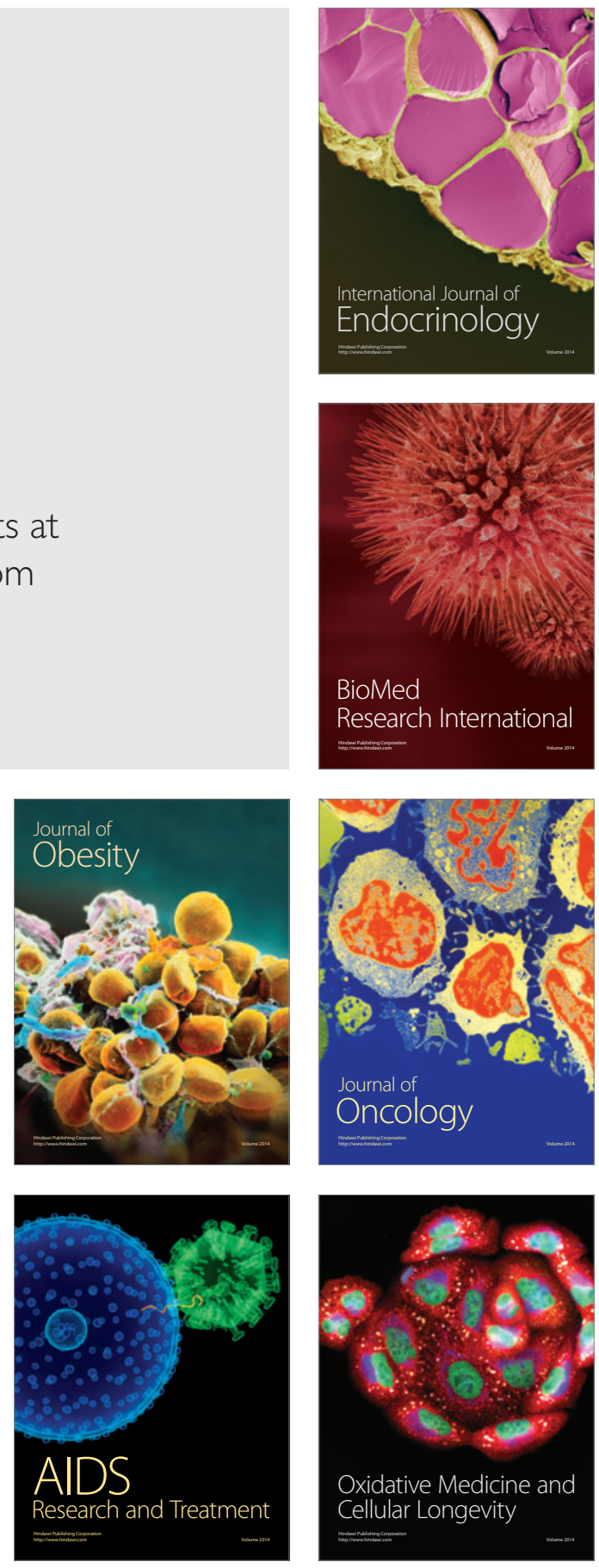